\title{
Congenital Depressed Skull Fracture Due to Maternal-Fetal Trauma
}

\section{Diallo Moussa1 ${ }^{*}$, Rabiou Mahaman Sani2, Tokpa André3, Ouattara Dramane1, Diallo Oumar4, Kanikomo Drissa ${ }^{1}$}

${ }^{1}$ Department of Neurosurgery, University hospital of Gabriel Touré, Bamako, Mali

${ }^{2}$ Department of Neurosurgery, National Hospital of Zender, Zender, Niger

${ }^{3}$ Department of Neurosurgery, University Hospital of Bouaké, Cote d'Ivoire

${ }^{4}$ Department of Neurosurgery, Hospital of Mali, Bamako, Mali

Email: ^mdiallo5@gmail.com, ^moussa.diallo@usttb.edu.ml

How to cite this paper: Moussa, D., Sani, R.M., André, T., Dramane, O., Oumar, D. and Drissa, K. (2021) Congenital Depressed Skull Fracture Due to Maternal-Fetal Trauma. Open Journal of Modern Neurosurgery, 11, $1-6$.

https://doi.org/10.4236/ojmn.2021.111001

Received: August 15, 2020

Accepted: December 6, 2020

Published: December 9, 2020

Copyright $\odot 2021$ by author(s) and Scientific Research Publishing Inc. This work is licensed under the Creative Commons Attribution International License (CC BY 4.0).

http://creativecommons.org/licenses/by/4.0/

\begin{abstract}
The fetal head trauma is rare and seen in pregnant road accidents and during extractive maneuvers during childbirth. We have reported a case of congenital depressed skull fracture due to an innocuous fall from her own height of a pregnant of 35 weeks of amenorrhea. The diagnosis was made at birth, by vaginal delivery, by the discovery of a left frontal depressed skull fracture without neurological disorder. A surgical lifting of the drepressed skull fracture was made at the 2 nd day of life. Outcome was good marked by a normal psychomotor development.
\end{abstract}

\section{Keywords}

Fetus, Head Trauma, Skull Depressed, Fracture

\section{Introduction}

Head traumas occurring in the fetus outside obstetrical maneuvers are rare and poorly documented [1]. Car accidents with pregnant women on board are the main cause of these injuries [2]. When they reach the head of the fetus, these traumas can be responsible for complications such as developmental delay or cerebral palsy. Depressed skull fractures of the fetus secondary to a fall of a pregnant woman from her own height are exceptional. We report a congenital depressed skull fracture due to maternal-fetal trauma. Through this case, we will discuss diagnostic and therapeutic modalities. 


\section{Case Report}

A 28-year-old woman, primiparous, second gesture patient consulted her gynecologist as a precaution following a fall from her own height which occurred the same day; after tripping over while walking. The reception took place on the left flank. She did not complain of abdominal pain or bleeding. Her medical and surgical history was unremarkable apart from a normal vaginal delivery 2 years earlier. The obstetric examination was normal. The fetal heart sounds were audible at a rate of 96 beats per minute (bpm) and active fetal movements were present. The amniotic fluid examination was not performed. An obstetric ultrasound performed had shown an ongoing pregnancy. The fetus was in cephalic presentation without apparent anomaly. There was no retroplacental hematoma. The patient returned to her home without any special observation. one month later, after an eutocic vaginal delivery, she gave birth to a male newborn weighing 3600 grams with an Apgar of 8 at one and five minutes. On examination of the newborn, it was found a large depression, roughly circular on the left frontal measuring 4.5 centimeters in diameter and a maximum depth of 3 centimeters. There was no contusion and no skin bruising next to the depressed skull fracture (Figure 1). The fontanelles were without particularity. The transfontanellar ultrasound (TFU) found no brain contusion or intracranial hematoma. The indication of a lifting of the depressed skull fracture was proposed urgently. The newborn was operated on the 2 nd day of life. This surgery consisted in making a drill hole one centimeter in diameter through an incision of 1.5 centimeters in the left frontal region at a few millimeters of the fracture (Figure 2). A Penfield dissector passing through the drill hole raised the depressed skull fracture by operating the lever. The operating procedure lasted 17 minutes. The baby was discharged from hospital 24 hours later. At 35 months of follow-up, the course was normal, marked by very good healing of the operating area and normal psychomotor development.
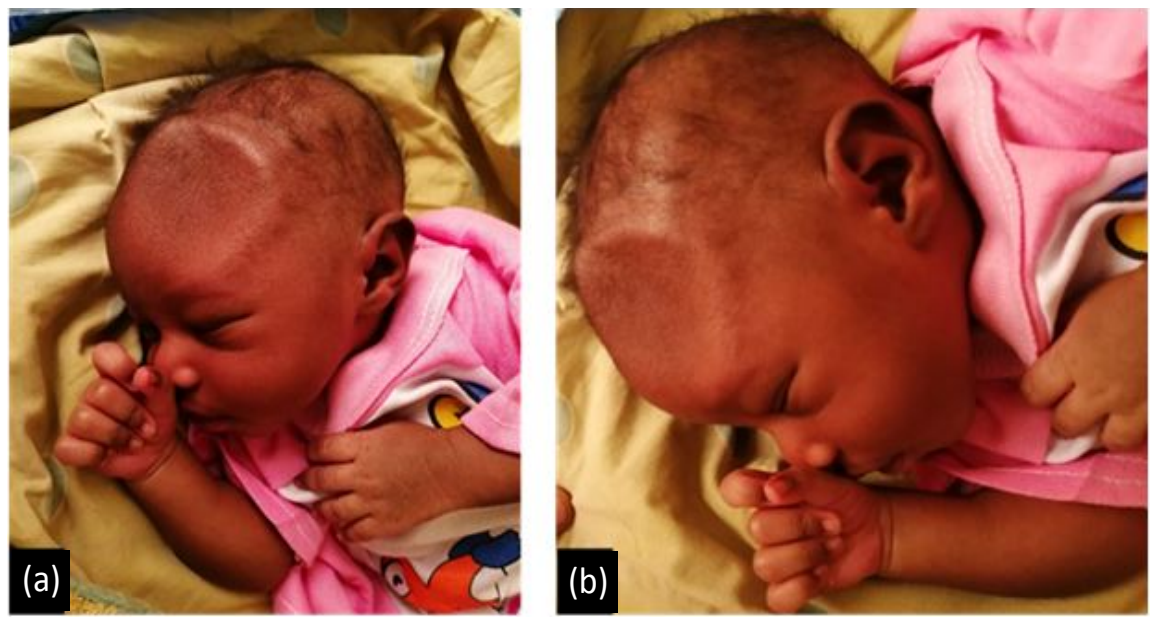

Figure 1. Picture of newborn child. (a) Newborn first day of life; (b) Important left frontal depressed skull fracture. 


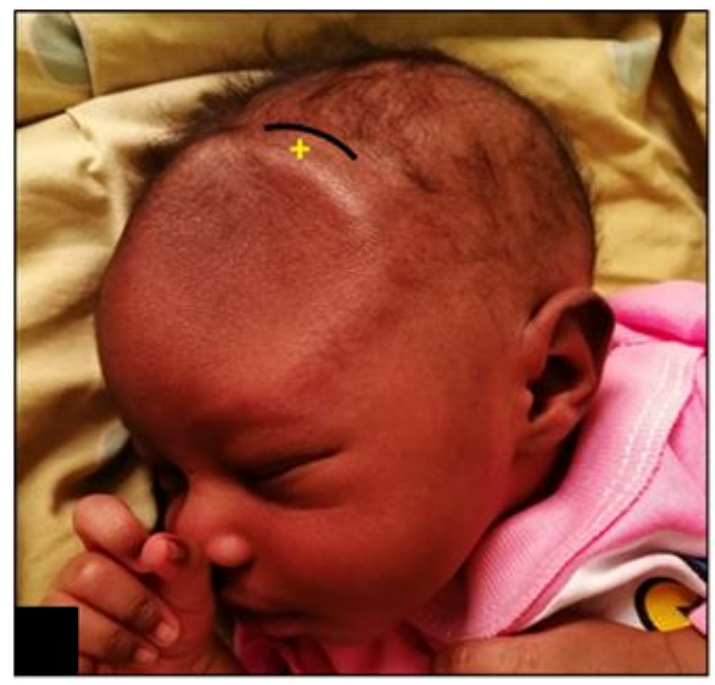

Figure 2. Surgical incision mark, 1.5 centimeters curved line of incision in frontal region + point of drill hole.

\section{Discussion}

Most trauma to the fetus are caused by car accidents, suicide, violence and war [3]. Motor vehicle accidents are the most common cause of trauma among pregnant women. They had concerned $2.8 \%$ of pregnant women in the United States [4]. Traumatic brain injuries can have a poor prognosis [5] [6]. They are often associated with a skull fracture and usually occur in the third trimester of pregnancy [6] [7]. The head trauma of the fetus due to the fall of the pregnant woman from her own height reported in our observation seems exceptional. We have not found a similar case in the literature. The depressed skull fracture of the left frontal bone of our fetus raises questions about its pathophysiology. Inside the uterus and in cephalic presentation, the fetus faces the spine so that its back and occipital region are facing forward. The fall of the pregnant with reception on the side should have caused a fracture of the occipital bone by direct impact and not of the left frontal bone. Therefore, depressed skull fracture could be the consequence of the frontal impact on the maternal spine. In case of suspected head trauma of the fetus, the gynecological and obstetric evaluation must include monitoring of his heart rate. This constitutes an appropriate method for checking his health state [8]. Changes in heart rate usually occur before the onset of fetal brain damage [9]. Examination of the amniotic fluid will help to identify abnormalities in favor of fetal distress. There is no specificity to suggest a fetal brain injury. An obstetric ultrasound in expert hands may be sufficient to make the antenatal diagnosis of lesions linked to a traumatic brain injury. It was not the case in our observation. In the immediate postnatal period, the transfontanellar ultrasound allowed us to evoke the absence of cerebral contusion and intracranial hemorrhage. Some authors have said that CT scan is the best test to assess posttraumatic brain damage to the fetus. According to them, the damage due to radiation would be much less than that caused by delayed diagnosis [8]. Others will go further by proposing a brain MRI [9] [10]. In our 
opinion, this examination would have a mainly prognostic value and we think that the transfontanellar ultrasound can be sufficient in certain cases to make the diagnosis of fetal cerebral lesions. Once the diagnosis has been made, management of the lesions becomes an emergency in order to avoid subsequent complications such as delayed neonatal development, hypotonia, blindness or even convulsions [8]. This therapeutic management most often involves surgery. Several operating techniques are possible, of which two are the most relevant. The minimal approach is the one we used in our observation (Figure 1). The best indication is a depressed skull fracture without cerebral lesions. The other option is to lift the depressed skull fracture through a large incision around the fracture, respecting the hairline and the vascular supply of the scalp (Figure 3). A craniectomy flap carrying the depressed skull fracture gives access to the underlying lesions which may be an extradural or subdural hematoma or even lesions of massive cerebral hemorrhagic contusion. Once the intracranial lesion is treated, the dura-mater is suspended and the cranial flap is returned to its place after the lifting of the depression. As in our patient, the result is good in case of early management in simple depressed skull fracture. The prognosis may be poor in the event of underlying lesions associated with the depressed skull fracture [6]. The treatment of these depressed skull fracture is controversial. It differs according to the authors. Indeed, some authors had proposed surgical abstention in view of the possibility of spontaneous reduction. Indeed, spontaneous resolution can occur because the skull of the newborn and the infant is thin and flexible and therefore susceptible to reshaping. [11]. Others, on the other hand, suggest surgical management. Between these 2 methods, there is resolution by suction maneuver, in particular using a suction cup or a breast pump. This last therapeutic modality, which can be done without general anesthesia, is not very aggressive and allows an immediate resolution [12] [13].

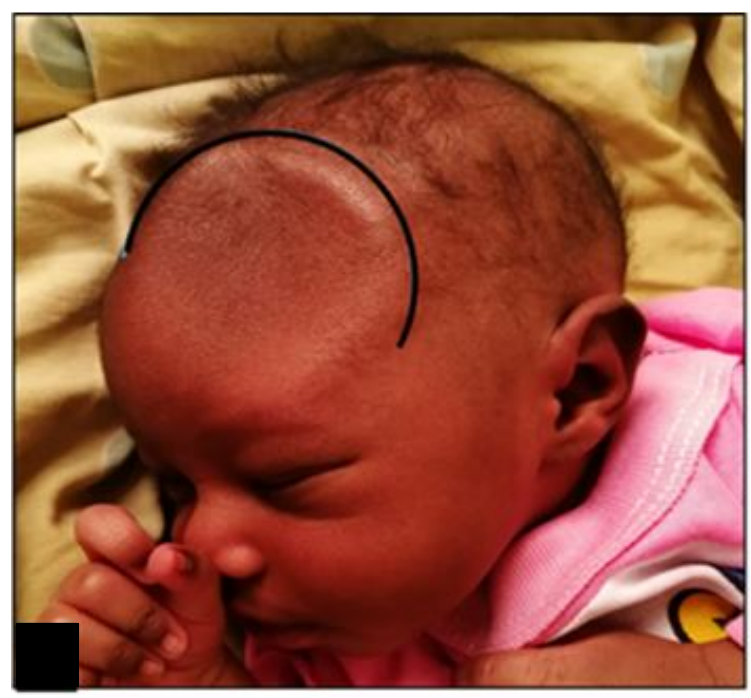

Figure 3. Surgical mark of large incision, Large incision around skull depressed fracture which permit to make a shutter and evacuated hematoma under the fracture. 


\section{Conclusion}

Congenital depressed skull fracture is a rare condition. Early diagnosis is possible in the antenatal period by carefully performed obstetric ultrasound. The severity of this condition is linked to the presence of underlying intracranial lesions. Emergency treatment will prevent or reduce neurological sequelae.

\section{Consent}

The informed consent of the parents has been obtained for the distribution of the images.

\section{Conflicts of Interest}

The authors declare no conflicts of interest regarding the publication of this paper.

\section{References}

[1] Chauvet, A., Boukerrou, M., Nayama, M., Dufour, P. and Puech, F. (2005) Traumatismes crâniens obstétricaux spontanés: Mythe ou réalité? Gynécologie $O b$ stétrique \& Fertilité, 33, 582-585. https://doi.org/10.1016/j.gyobfe.2005.06.018

[2] Abbasi, H.R., Mousavi, S.M., Taheri Akerdi, A., Niakan, M.H., Bolandparvaz, S., et al. (2013) Pattern of Traumatic Injuries and Injury Severity Score in a Major Trauma Center in Shiraz, Southern Iran. Bulletin of Emergency and Trauma, 1, 81-85.

[3] Leroy-Malherbe, V., Bonnier, C., Papiernik, E., Groos, E. and Landrieu, P. (2013) The Association between Developmental Handicaps and Traumatic Brain Injury during Pregnancy: An Issue That Deserves More Systematic Evaluation. Brain Injury, 20, 1355-1365. https://doi.org/10.1080/02699050601102202

[4] Hyde, L.K., Cook, L.J., Olson, L.M., Weiss, H.B. and Dean, J.M. (2003) Effect of Motor Vehicle Crashes on Adverse Fetal Outcomes. Obstetrics \& Gynecology, 102, 279-286. https://doi.org/10.1097/00006250-200308000-00013

[5] Nishida, N., Ina, S., Hata, Y., Nakanishi, Y., Ishizawa, S., et al. (2018) Fetal Closed Head Injuries Following Maternal Motor Vehicle Accident. A Clinicopathologic Case Report. Medicine (Baltimore), 97, e13133. https://doi.org/10.1097/MD.0000000000013133

[6] Sadro, C.T., Zins, A.M., Debiec, K. and Robinson, J. (2012) Case Report: Lethal Fetal Head Injury and Placental Abruption in a Pregnant Trauma Patient. Emergency Radiology, 19, 175-180. https://doi.org/10.1007/s10140-011-1017-9

[7] Breysem, L., Cossey, V. and Mussen, E. (2012) Fetal Trauma: Brain Imaging in Four Neonates. European Radiology, 14, 1609-1614.

https://doi.org/10.1007/s00330-004-2357-6

[8] Safdari, M., Safdari, Z. and Pishjoo, M. (2012) Intrauterine Fetal Traumatic Brain Injury Following Motor Vehicle Accident: A Case Report and Review of the Literature. Bulletin of Emergency and Trauma, 6, 372-375.

https://doi.org/10.29252/beat-060417

[9] Matsushita, H., Harada, A., Sato, T. and Kurabayashi, T. (2014) Fetal Intracranial Injuries Following Motor Vehicle Accidents with Airbag Deployment. Journal of Obstetrics and Gynaecology Research, 40, 599-602. 
https://doi.org/10.1111/jog.12188

[10] Yamasato, K., Kurata, N. and Towner, D. (2018) Delayed Appearance of a Traumatic Fetal Intracranial Hemorrhage. Case Reports in Obstetrics and Gynecology, 2018, Article ID 1465034. https://doi.org/10.1155/2018/1465034

[11] Agrawal, S.K., Kumar, P. and Sundaram, V. (2010) Congenital Depression of the Skull in Neonate: A Case of Successful Conservative Management. Journal of Child Neurology, 25, 387-389. https://doi.org/10.1177/0883073809338520

[12] Mastrapa, T.L., Fernandez, L.A., Alvarez, M.D., Storrs, B.B. and Flores-Urueta, A. (2007) Depressed Skull Fracture in Ping Pong: Elevation with Medeva Extractor. Child s Nervous System, 23, 787-790. https://doi.org/10.1007/s00381-007-0354-1

[13] Saunders, B.S., Lazoritz, S., McArtor, R.D., Marshall, P. and Bason, W.M. (1979) Depressed Skull Fracture in the Neonate. Report of 3 Cases. Journal of Neurosurgery, 50, 512-514. https://doi.org/10.3171/jns.1979.50.4.0512 